\title{
Polysilsesquioxanes for Gate-Insulating Materials of Organic Thin-Film Transistors
}

\author{
Kimihiro Matsukawa, ${ }^{1}$ Mitsuru Watanabe, ${ }^{1}$ Takashi Hamada, ${ }^{2}$ \\ Takashi Nagase, ${ }^{3}$ and Hiroyoshi Naito ${ }^{3}$ \\ ${ }^{1}$ Electronic Material Research Division, Osaka Municipal Technical Research Institute, Osaka 536-8553, Japan \\ ${ }^{2}$ JST Innovation Plaza Osaka, Osaka 594-1131, Japan \\ ${ }^{3}$ Department of Physics and Electronics, Osaka Prefecture University, Osaka 599-8531, Japan
}

Correspondence should be addressed to Kimihiro Matsukawa, kmatsu@omtri.or.jp

Received 11 August 2012; Accepted 11 September 2012

Academic Editor: Yoshiro Kaneko

Copyright (C) 2012 Kimihiro Matsukawa et al. This is an open access article distributed under the Creative Commons Attribution License, which permits unrestricted use, distribution, and reproduction in any medium, provided the original work is properly cited.

\begin{abstract}
Printable organic thin-film transistor (O-TFT) is one of the most recognized technical issues nowadays. Our recent progress on the formation of organic-inorganic hybrid thin films consists of polymethylsilsesquioxane (PMSQ), and its applications for the gateinsulating layer of O-TFTs are introduced in this paper. PMSQ synthesized in toluene solution with formic acid catalyst exhibited the electric resistivity of higher than $10^{14} \Omega \mathrm{cm}$ after thermal treatment at $150^{\circ} \mathrm{C}$, and the very low concentration of residual silanol groups in PMSQ was confirmed. The PMSQ film contains no mobile ionic impurities, and this is also important property for the practical use for the gate-insulating materials. In the case of top-contact type TFT using poly(3-hexylthiophene) (P3HT) with PMSQ gate-insulating layer, the device properties were comparable with the TFTs having thermally grown $\mathrm{SiO}_{2}$ gate-insulating layer. The feasibility of PMSQ as a gate-insulating material for O-TFTs, which was fabricated on a flexible plastic substrate, has been demonstrated. Moreover, by the modification of PMSQ, further functionalities, such as surface hydrophobicity, high permittivity that allows low driving voltage, and photocurability that allows photolithography, could be appended to the PMSQ gate-insulating layers.
\end{abstract}

\section{Introduction}

Organic thin-film transistor (O-TFT) is an indispensable component in the development of large-area, flexible, and low-cost electronic devices, such as paper-like displays, radio frequency identification tags, and high-performance sensors. However, as the conventional method of O-TFT fabrication, which includes multiple steps of vacuum processing, is complicated and costly, the convenient fabrication process for OTFT is required in the industrial demand. Thus, the solution based method has attracted increasing attention to achieve low-cost fabrication of O-TFTs. Printable organic semiconductors have been widely investigated $[1,2]$ and the wide technology for printed electronics is progressing rapidly. As a solution processible gate-insulating layer for O-TFT devices, various organic polymers have been examined, including polyvinylphenol (PVP) [3, 4], polymethylmethacrylate [5], polyimide [6], and polyvinylalcohol [7], so far. Since organic polymer based gate-insulating materials exhibited lower electric and chemical resistivity than that of inorganic dielectrics, those organic polymers are not the optimum material for the insulating layer of multilayered electronic devices. On the other hand, organic-inorganic hybrid materials will be the most promising materials that can solve these problems, because organic-inorganic hybrids are expected to have specific properties derived from both organic and inorganic component, that is, solution processibility, flexibility, and high resistivity. In the point of view from organic-inorganic hybrids, we have developed novel organic-inorganic hybrid materials that can make a gate-insulating layer of O-TFT by a simple solution process. In this paper, our recent progresses on the construction of organic-inorganic hybrid thin films consist of polysilsesquioxane, and its applications for the gate-insulating layer of O-TFTs are introduced. 


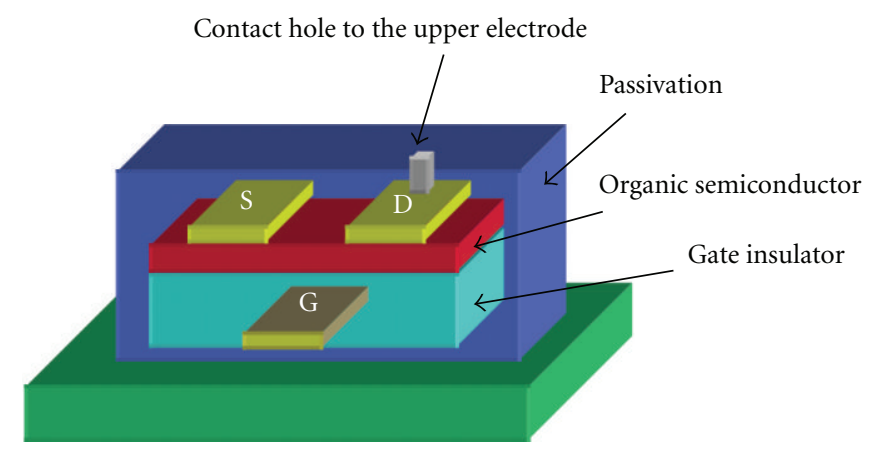

FIGURE 1: Device structure of O-TFT (bottom-gate/top-contact type).
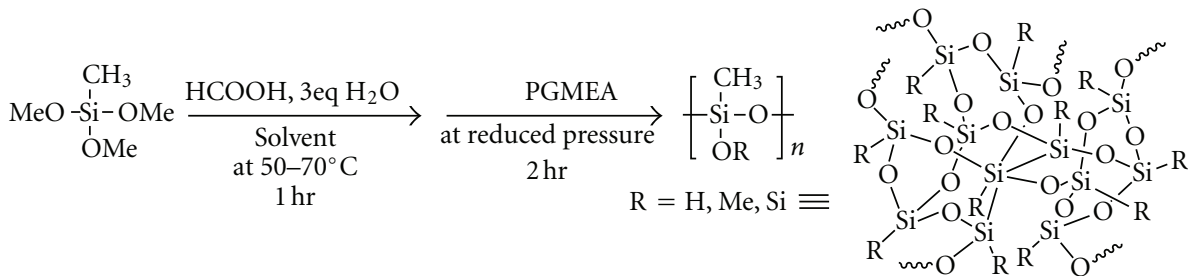

FIGURE 2: Synthesis of polymethylsilsesquioxane (PMSQ).

\section{Required Properties of Gate-Insulating Layer for 0-TFT}

As shown in Figure 1, a bottom-gate/top-contact type OTFT consists of a gate electrode, gate-insulating layer, organic semiconductor layer, and source and drain electrodes, respectively. Furthermore, in order to keep the high durability of O-TFT component, the O-TFT must be covered by a passivation layer, and an upper electrode is formed on the passivation layer. The upper electrode is connected with the drain electrode through a contact hole in the passivation layer, which transfers electric signals from O-TFT to a driving electrode of devices such as liquid crystal or electric paper ink. In those components of O-TFT, electric resistivity and permittivity of the gate-insulating layer are known to largely affect the electric performance of the O-TFT, because charge transfer through the channel, that is, the gap between the source and drain electrodes, is strictly controlled by applied gate-voltage $\left(V_{G}\right)$, which induces electric field through the gate-insulating layer and results in charge accumulation at the interface between the gate-insulating layer and the organic semiconductor layer. In general, the well-known inorganic gate-insulating films, such as silicon nitrate by plasma CVD [8], aluminum oxide [9], and tantalum oxide [10] by sputter process, are prepared by a costly hightemperature vacuum process. There is a requirement of optimized material for gate-insulating layer to manufacture highperformance O-TFTs. In case of fabricating O-TFT onto flexible plastic substrates, the most important requirement is a low-temperature curability, since there is a limitation of process temperature. As a material must form a cross-linked thin film at relatively low temperature, polysilsesquioxane has been recognized as a promising candidate [11-15]. However, previous attempts resulted in low electric resistivity and stability $[14,15]$, because residual silanol groups in polysilsesquioxane have not condensed completely. It is indispensable for polysilsesquioxane to solve this problem, in order to apply as gate-insulating material of O-TFTs. In addition, gate-insulating materials are also required to be low ionic impurity concentration, high permittivity, high-surface smoothness, low-surface free energy, and so forth. We have developed novel polysilsesquioxanes that accomplished these requirements.

\section{Synthesis of Polymethylsilsesquioxane (PMSQ)}

Materials for gate-insulating layer of O-TFTs should exhibit high electric resistivity (more than $10^{13} \Omega \mathrm{cm}$ ) and high permittivity. As a possible material for such requirements, we investigated polymethylsilsesquioxane (PMSQ) that can be synthesized by sol-gel condensation of methyltrimethoxysilane (Figure 2). In order to develop highly cross-linked PMSQ films with low concentration of residual silanol groups, which have reduced electric resistivity, PMSQ was synthesized under various reaction conditions [16]. ${ }^{1} \mathrm{H}-$ NMR spectra of PMSQ prepared in methanol and toluene are shown in Figure 3. The amounts of silanol $\mathrm{Si}-\mathrm{OH}$ were estimated based on the amount of silylmethyl group Si$\mathrm{CH}_{3}$, revealing that silanol content was extremely small when PMSQ was prepared in toluene compared to that in 


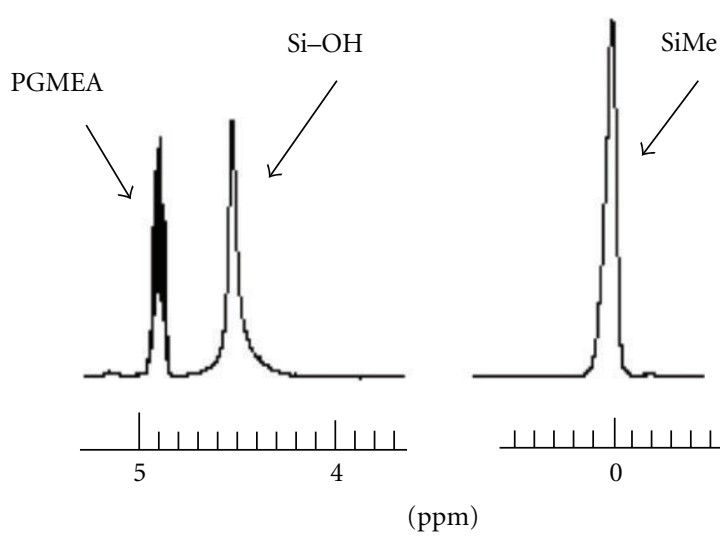

(a) In $\mathrm{MeOH}$

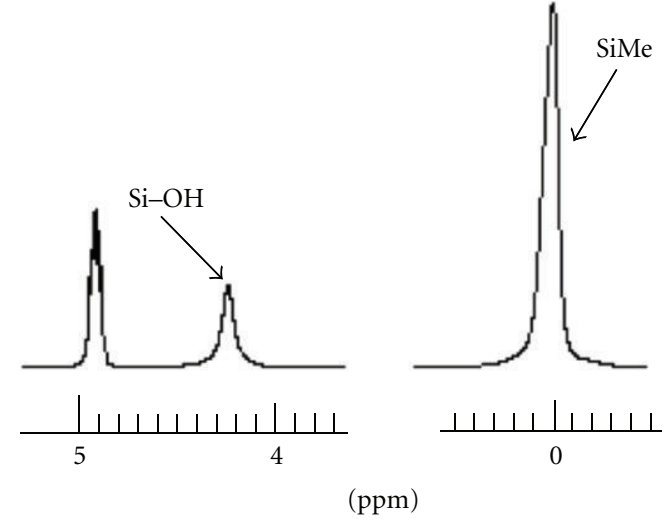

(b) In Toluene

FiguRE 3: ${ }^{1} \mathrm{H}-\mathrm{NMR}$ spectra of PMSQ; (a) prepared in methanol, (b) prepared in toluene.

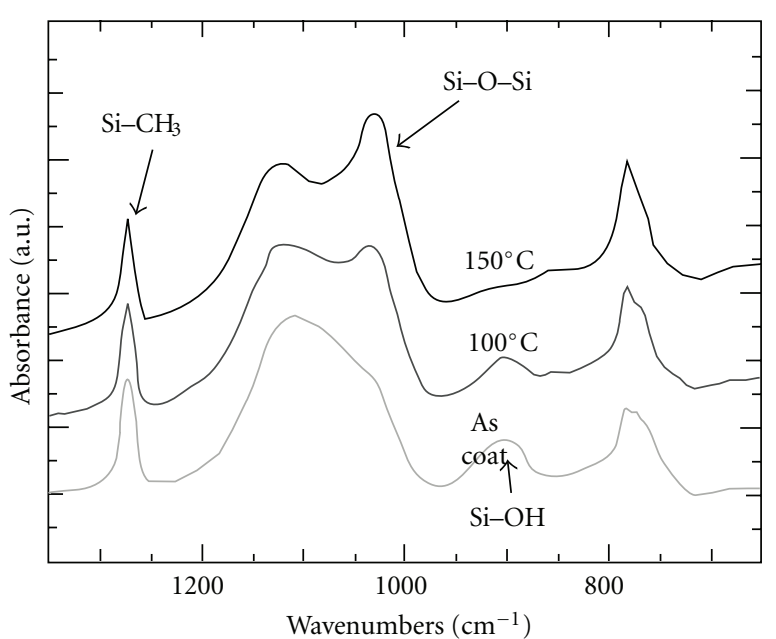

FIGURE 4: FT-IR spectra of PMSQ films before and after thermal treatment at $100^{\circ} \mathrm{C}$ and $150^{\circ} \mathrm{C}$ for $1 \mathrm{~h}$ in air.

methanol. Also by a measurement of ${ }^{29} \mathrm{Si}-\mathrm{NMR}$, the amount of highly cross-linked $\mathrm{T}^{3}$ structure, which is corresponding to the silicon atom attached to one alkyl group and three siloxane groups, was twice larger in toluene than that in methanol. This observation indicates also low concentration of silanol groups. It is found that these results were caused by the difference of the polarity of solvents. In the case of the solgel reaction under hydrophobic condition in toluene, the collision frequency of silanol groups will increase by hydrophilic interaction, so that enhances the condensation reaction rate, leading to a decrease in the silanol concentration. On the other hand, the excessive water or methanol molecules in the reaction mixture will stabilize silanol groups, which interfere with the condensation reaction to PMSQ with less residual silanols. Therefore, the condensation was carried out under reduced pressure, as shown in Figure 2, to remove methanol and water from propylene glycol monomethyl ether acetate (PGMEA) solution. For the practical use of PMSQ as
TABle 1: Properties of PMSQ prepared in different solvents.

\begin{tabular}{lccccc}
\hline Solvent & Temperature $\left({ }^{\circ} \mathrm{C}\right)$ & $\mathrm{Mw}^{\mathrm{a}}$ & $\mathrm{Mw} / \mathrm{Mn}$ & $\varepsilon(10 \mathrm{kHz})^{\mathrm{b}}$ & $\Omega \mathrm{cm}^{\mathrm{b}}$ \\
\hline $\mathrm{MeOH}$ & 50 & 6150 & 8.31 & 5.4 & $7.2 \times 10^{12}$ \\
Toluene & 50 & 4700 & 5.79 & 4.2 & $1.6 \times 10^{14}$ \\
PGMEA & 70 & 3960 & 3.46 & 4.3 & $3.8 \times 10^{13}$ \\
\hline
\end{tabular}

${ }^{a}$ Estimated by GPC in THF using polystyrene standards.

${ }^{\mathrm{b}}$ Baking temperature: $150^{\circ} \mathrm{C}$.

a gate-insulating material, PMSQ solution should be coated onto the gate electrode, and the thin film was baked to complete consumption of residual silanols. Figure 4 shows the FT-IR spectra of spin-coated PMSQ films before and after thermal treatment at 100 and $150^{\circ} \mathrm{C}$ for $1 \mathrm{~h}$ in air. The absorption bands at $902 \mathrm{~cm}^{-1}, 1030 \mathrm{~cm}^{-1}$, and $1270 \mathrm{~cm}^{-1}$ are attributed to the bonds of $\mathrm{Si}-\mathrm{OH}, \mathrm{Si}-\mathrm{O}-\mathrm{Si}$, and $\mathrm{Si}-$ $\mathrm{CH}_{3}$, respectively. The absorption peak of the silanol groups $(\mathrm{Si}-\mathrm{OH})$ disappeared completely, and the intensity of the siloxane bonds ( $\mathrm{Si}-\mathrm{O}-\mathrm{Si})$ markedly increased on thermal treatment at $150^{\circ} \mathrm{C}$ [17]. This result clearly indicated that the cross-linking reaction of the silanol groups proceeded effectively even at low-temperature treatment less than $150^{\circ} \mathrm{C}$, forming the higher cross-linked siloxane network.

Electric resistivity and permittivity of PMSQ thin films prepared in different solvents were measured using Al/PMSQ/Al cell structures fabricated on glass substrates and summarized in Table 1. It was found that the electrical resistivity of PMSQ thin films significantly changed in the range from $10^{12}$ to $10^{14} \Omega \mathrm{cm}$ depending on the organic solvent used in the synthesis. The PMSQ synthesized in toluene exhibited a high resistivity of $1.6 \times 10^{14} \Omega \mathrm{cm}$, which were two orders of magnitude higher than that synthesized in methanol. Current density-electric field characteristics shown in Figure 5(a) also revealed the formation of dense siloxane networks in the PMSQ film which were cured at $150^{\circ} \mathrm{C}$. The PMSQ film had a very high breakdown field of over $3.0 \mathrm{MV} \mathrm{cm}^{-1}$ and exhibited an extremely low leakage current, which was much lower than that of 


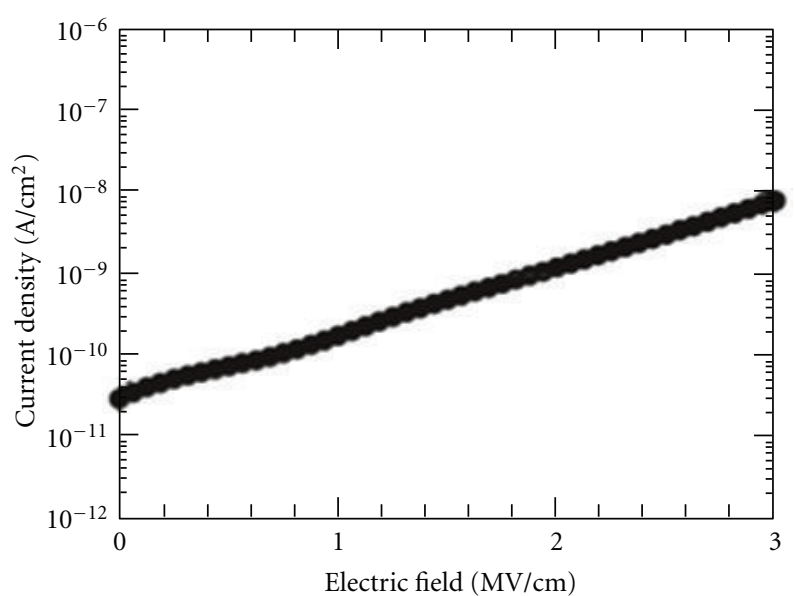

(a)

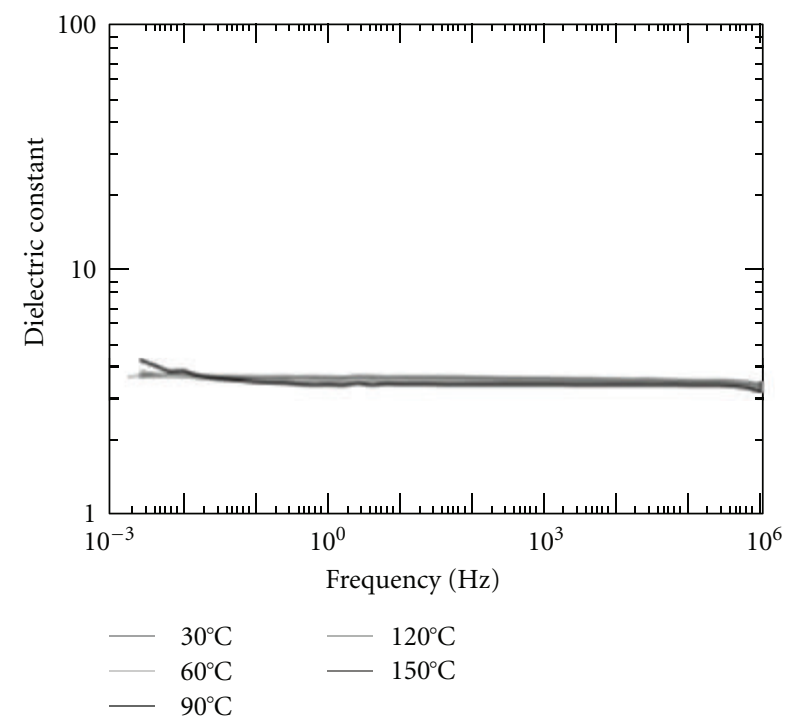

(b)

Figure 5: (a) Current density-electric field characteristics and (b) frequency dependence of dielectric constant of PMSQ film cured at $150^{\circ} \mathrm{C}$ for $1 \mathrm{~h}$ in air.

PVP and polyimide [18] and more than two orders of magnitude lower than that of previously reported PMSQ films [14]. Furthermore, since mobile ionic impurities in gate-insulating layer seriously suffer the property of $\mathrm{O}$ TFTs, it is important to confirm their existence by means of impedance spectroscopy, that is, measurement of permittivity as a function of frequency in wide range of temperature [19]. As shown in Figure 5(b), the dielectronic constant $(k \sim 3.6)$ did not significantly change for wide frequency sweeps $(10 \mathrm{mHz} \sim 100 \mathrm{kHz})$ and wide temperature sweeps $\left(30 \sim 150^{\circ} \mathrm{C}\right)$, which indicated extremely low concentration of mobile ionic impurities. The reason of the absence of mobile ionic impurities is probably due to the preparation condition of PMSQ. The novel synthetic process introduced here utilizes formic acid as a volatile acid catalyst for the solgel reaction, and after the condensation, it was completely removed under reduced pressure with exchanging the solvent by adding PGMEA of higher boiling point.

The PMSQ thin films, which were made by spin-coating and subsequent thermal treatment at $150^{\circ} \mathrm{C}$, were not dissolved in common organic solvents such as chloroform, toluene, and xylene, which allows the next coating of soluble organic semiconductors, such as poly(3-hexylthiophene) (P3HT), onto the PMSQ gate-insulating layer. The PMSQ thin films have the pinhole-less smooth surface with average roughness of $0.24 \mathrm{~nm}$, which came out by AFM measurements. Relatively less volatile nature of PGMEA and fluidity of PMSQ before the thermal treatment will be attributable to this surface smoothness of the thin films. Moreover, PMSQ film had a hydrophobic surface exhibiting the water contact angle of $90.7^{\circ}$, and this also satisfies one of the requirements for the gate-insulating layer of O-TFTs.

\section{Characteristics of PMSQ as a Gate-Insulating Material}

Top-contact P3HT TFTs with gate-insulating layer of PMSQ were fabricated on a glass substrate with an indium-tinoxide (ITO) gate electrode. The spin-coated PMSQ thin films were cured at $150^{\circ} \mathrm{C}$ for $1 \mathrm{~h}$ in ambient air, which were $450 \mathrm{~nm}$ in thickness. A solution of regioregular P3HT in chloroform was spin-coated onto the gate-insulating layer, and the source and drain electrodes were evaporated onto the P3HT layer through a shadow mask, as shown in Figure 6 for TFT structure. Figure 7 shows the $I_{D}-V_{D}$ output curves and $I_{D}-V_{G}$ transfer curves of the P3HT TFT with PMSQ gate-insulating layer (where $I_{D}, V_{D}$, and $V_{G}$ stand for drain current, drain voltage, and gate voltage, resp.). In Figure $7(a)$, all curves display good linear and saturation behaviors with no leakage current at $V_{D}=0 \mathrm{~V}$. Figure 7 (b) shows that the device exhibited no hysteresis with respect to a $V_{G}$ sweep from +20 to $-80 \mathrm{~V}$ and then from -80 to $+20 \mathrm{~V}$, indicating that P3HT TFT with PMSQ gateinsulating layer has stable TFT characteristics significantly. For comparison, P3HT TFT using a highly doped Si substrate with a thermally grown $\mathrm{SiO}_{2}$ gate-insulating layer $(365 \mathrm{~nm}$ thickness) were also fabricated. The surfaces of the $\mathrm{SiO}_{2}$ gateinsulating layers were modified with the hydrophobic selfassembled monolayers (SAMs) of alkyltrichlorosilanes with different alkyl lengths $\left(\mathrm{C}_{n} \mathrm{H}_{2 n+1}-\mathrm{SiCl}_{3}, n=2,6,12\right.$, and 18). The field-effect mobility $(\mu)$ and induced threshold voltage $\left(V_{\text {th }}\right)$ shift for the $V_{G}$ sweep of the devices with different gate-insulating layer surfaces are summarized in Table 2. P3HT TFT with PMSQ gate-insulating layer exhibited fair TFT characteristics with $\mu=7.1 \times 10^{-3} \mathrm{~cm}^{2} \mathrm{~V}^{-1} \mathrm{~s}^{-1}$ and $V_{\text {th }}=-0.3 \mathrm{~V}$, whereas the device with untreated $\mathrm{SiO}_{2}$ gateinsulating layer exhibited one order magnitude of small mobility and larger negative $V_{\text {th }}$ shift because of hydrophilic surface. The suppression of hysteresis behavior and smaller negative $V_{\text {th }}$ shift of the device with PMSQ gate-insulating layer also indicates that cured PMSQ films may contain a small number of uncross-linked residual silanol groups. The mobility of SAM-modified $\mathrm{SiO}_{2}$ gate-insulating layer showed a close correlation to the water contact angle; that is, a more 


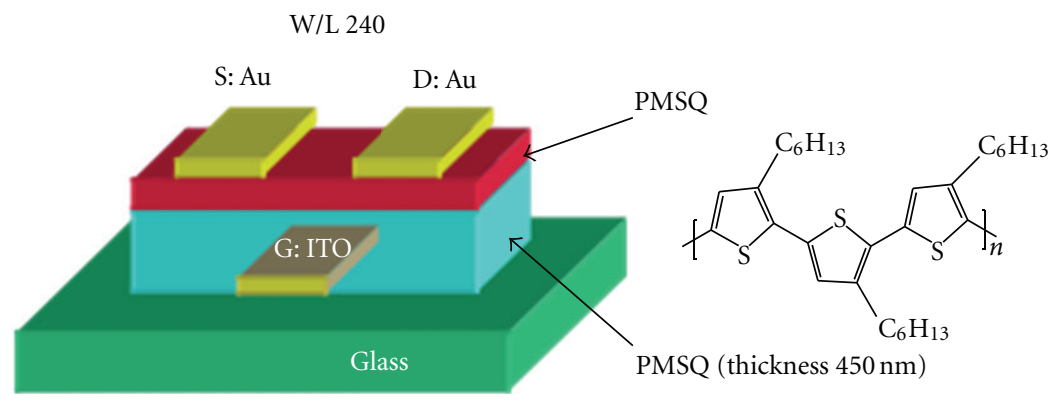

FIGURE 6: O-TFT (bottom-gate/top-contact type) with PMSQ and P3HT.

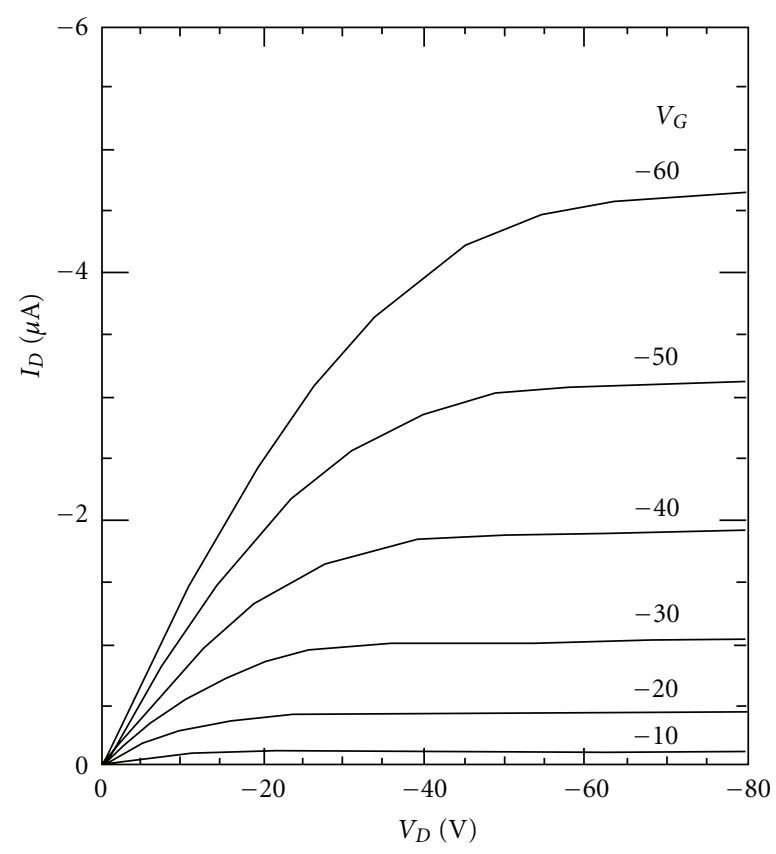

(a)

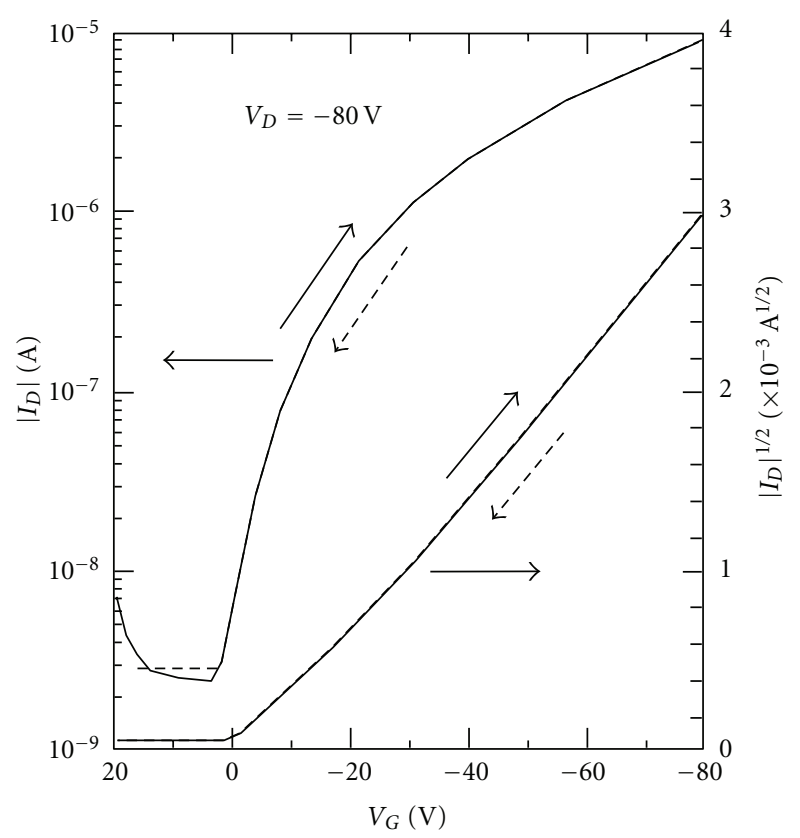

(b)

FIgURE 7: (a) Output and (b) transfer characteristics of P3HT TFT with PMSQ gate insulator.

hydrophobic surface gives a higher mobility. Such behavior has been observed by a number of authors, indicating that mobility enhancement is caused by the improvement in the structural ordering of the $\mathrm{P} 3 \mathrm{HT}$ molecules at low-energy surfaces [20-22]. A large contact angle of the PMSQ surfaces would originate from the high density of the methyl groups and the small amount of the residual Si-OH groups, which are responsible for enhanced mobility.

As described above, the spin-coated thin films of PMSQ can be cured at a low temperature of $150^{\circ} \mathrm{C}$, which is suitable for a plastic substrate. Thus, fabrications of $\mathrm{O}-$ TFTs on flexible plastic substrates were also investigated. Polycarbonate (PC) substrate coated with an indium zinc oxide (IZO) layer was prepatterned by wet etching and used as a gate electrode, a gate-insulating layer of PMSQ was formed by spin-coating and subsequent thermal treatment, followed by spin-coating of P3HT, and source and drain electrodes were thermally deposited [23]. The P3HT TFT fabricated on PC substrate exhibited field-effect mobility
TABle 2: Mobility $(\mu)$ and $V_{\text {th }}$ with respect to $V_{G}$ sweep of P3HT TFTs and water contact angle on different insulator surfaces. The alkyltrichlorosilane SAMs are represented as number of alkyl units $(n)$.

\begin{tabular}{lccc}
\hline $\begin{array}{l}\text { Gate } \\
\text { insulator }\end{array}$ & $\mu\left(\mathrm{cm}^{2} \mathrm{~V}^{-1} \mathrm{~s}^{-1}\right)$ & $\begin{array}{r}\text { Water contact } \\
\text { angle (degree) }\end{array}$ & $V_{\text {th }}(\mathrm{V})$ \\
\hline PMSQ & $7.1 \times 10^{-3}$ & 93 & -0.3 \\
$\mathrm{SiO}_{2}$ & $7.8 \times 10^{-4}$ & 25 & -2.0 \\
$n=2$ & $4.2 \times 10^{-3}$ & 89 & -2.5 \\
$n=6$ & $1.2 \times 10^{-2}$ & 103 & -2.5 \\
$n=12$ & $3.0 \times 10^{-2}$ & 106 & -2.4 \\
$n=18$ & $3.3 \times 10^{-2}$ & 107 & -2.4 \\
\hline
\end{tabular}

of $\mu=5.8 \times 10^{-3} \mathrm{~cm}^{2} \mathrm{~V}^{-1} \mathrm{~s}^{-1}$, which was comparable to those of the devices fabricated on glass substrates. Also, on a polyethylenenaphtalate (PEN) substrate, P3HT TFT with 


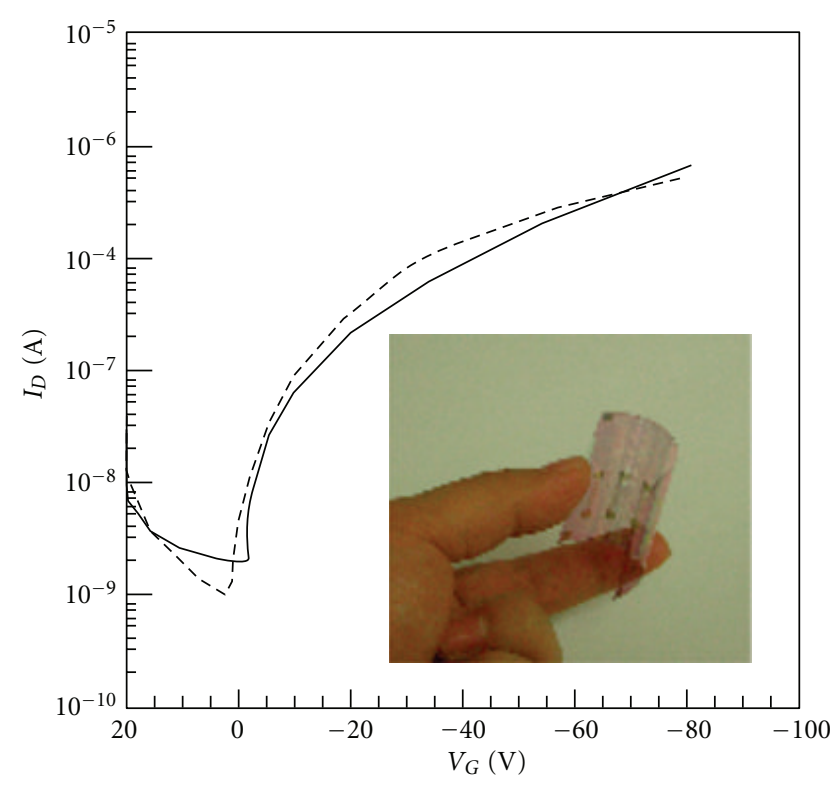

FIGURE 8: Transfer characteristics of P3HT TFT fabricated on glass substrate (solid line) and PEN substrate (dashed line) at $V_{D}=$ $-80 \mathrm{~V}$. Inset: An image of TFT device on PEN substrate $\left(5 \times 5 \mathrm{~cm}^{2}\right)$.

PMSQ gate-insulating layer has been similarly fabricated [24]. As shown in Figure 8, the transfer characteristic curves of P3HT TFT on a glass substrate and that on a PEN substrate were almost equal each other. The field effect mobility and on/off ratio were also comparable with different substrates as summarized in Table 3 . These results demonstrate that low-temperature processible PMSQ is extremely useful gateinsulating material for enhancing electrical stability as well as for a fabrication of printable O-TFTs.

\section{Functionalization of PMSQ Gate-Insulating Layer}

5.1. Control of Surface Hydrophobicity of PMSQ. As mentioned above, SAM modification on utilizing a thermally grown $\mathrm{SiO}_{2}$ layer as a gate-insulating layer is essential step for the higher performance of O-TFT. Similarly, we studied to improve the TFT properties by the SAM modification of PMSQ surface [25]. PMSQ was spin-coated on the glass substrates and heated at $80^{\circ} \mathrm{C}$ for $2 \mathrm{~min}$. At this stage, PMSQ thin films were not completely cured and the silanol could clearly be observed by IR measurement, but as the crosslinked films were not dissolved in organic solvents, the SAM modification could be performed with the remaining silanol group on the surface of PMSQ thin film. After PMSQ thin film on the substrate were immersed in the $5 \mathrm{wt} . \%$ various alkyltrichlorosilanes of hexane/chloroform $(3: 1)$ solution and then washed with hexane as shown in Figure 9, which is a stepwise modification. In order to complete the modification and curing of PMSQ, the substrate was heated at $150^{\circ} \mathrm{C}$ for $1 \mathrm{~h}$.
TABle 3: Device performance (mobility, on/off ratio, and $V_{\text {th }}$ ) of P3HT TFT on glass and PEN substrate with PMSQ as the gate insulating layers.

\begin{tabular}{lccc}
\hline Substrate & $\mathrm{m}\left(\mathrm{cm}^{2} \mathrm{~V}^{-1} \mathrm{~s}^{-1}\right)$ & $V_{\text {th }}(\mathrm{V})$ & On/off ratio \\
\hline Glass & $4.0 \times 10^{-3}$ & -18 & $4.0 \times 10^{3}$ \\
PEN & $1.3 \times 10^{-3}$ & 5 & $4.0 \times 10^{3}$ \\
\hline
\end{tabular}

TABLE 4: Surface properties of co-PMSQ thin films.

\begin{tabular}{|c|c|c|c|}
\hline \multicolumn{2}{|c|}{ Additive $\left[\mathrm{R}-\mathrm{Si}(\mathrm{OMe})_{3}\right]$} & \multirow{2}{*}{$\begin{array}{c}\text { Contact angle } \\
\text { (degree) }\end{array}$} & \multirow{2}{*}{$\begin{array}{l}\text { Surface free energy } \\
\qquad\left(\mathrm{mJ} \mathrm{m}^{-2}\right)\end{array}$} \\
\hline $\mathrm{R}$ & $\mathrm{mol} \%$ & & \\
\hline None & - & 86.1 & 28.2 \\
\hline$-\left(\mathrm{CH}_{2}\right)_{17} \mathrm{CH}_{3}$ & 0.5 & 87.1 & 28.5 \\
\hline$-\left(\mathrm{CH}_{2}\right)_{2} \mathrm{Ph}$ & 0.5 & 89.6 & 27.1 \\
\hline$-\left(\mathrm{CH}_{2}\right)_{2}\left(\mathrm{CF}_{2}\right)_{5} \mathrm{CF}_{3}$ & 0.5 & 92.9 & 24.3 \\
\hline$-\left(\mathrm{CH}_{2}\right)_{2}\left(\mathrm{CF}_{2}\right)_{5} \mathrm{CF}_{3}$ & 1.0 & 97.1 & 22.3 \\
\hline
\end{tabular}

In the case of SAM modification using octadecyltrichlorosilane (OTS), signals of silanol on IR spectra completely disappeared lower than $150^{\circ} \mathrm{C}$ of thermal treatment, and the film exhibited higher water contact angle of $100^{\circ}$, whereas the nonmodified PMSQ films show lower water contact angle of $89^{\circ}$. To examine the effect of surface modification of PMSQ for O-TFT performance, O-TFTs were fabricated using the nontreated PMSQ and the OTStreated PMSQ thin films as gate-insulating layers. Figures 10(a) and 10(b) show the output characteristics of P3HT TFTs with the non-treated PMSQ and OTS-treated PMSQ films, respectively. The O-TFT with the OTS-treated PMSQ thin films showed higher mobility and larger on/off ratio compared to that with the nontreated PMSQ films. It will be noteworthy that the mobility of the O-TFT with OTS-treated PMSQ was 4 times larger than that with nontreated PMSQ.

Instead of the SAM modification of PMSQ surface, copolymethylsilsesquoxanes (co-PMSQs), which were prepared from cocondensation of methyltrimethoxysilane and a small amount of alkyltrimethoxysilanes, were used for the direct formation of hydrophobic surface [26]. And coPMSQ gate-insulating layers were fabricated by a simple spin-coating and subsequent thermal treatment as shown in Figure 11. The relation between the surface free energy of co-PMSQ layer and field effect mobility was investigated. The surface properties of co-PMSQ with several alkyl groups were summarized in Table 4, and it seems that the surface of co-PMSQ thin films were more hydrophobic than that of normal PMSQ, indicating that hydrophobic functional groups migrated and accumulated on the surface. Especially, co-PMSQ derived from tridecafuluoro-1,1,2,2tetrahydrooctyltrimethoxysilane exhibited very low surface free energy.

Figure 12 shows the relation between the surface free energy and mobility of the O-TFTs fabricated with the coPMSQ gate-insulating layer. It could be clearly observed that the mobility increased with lower surface free energy. This 


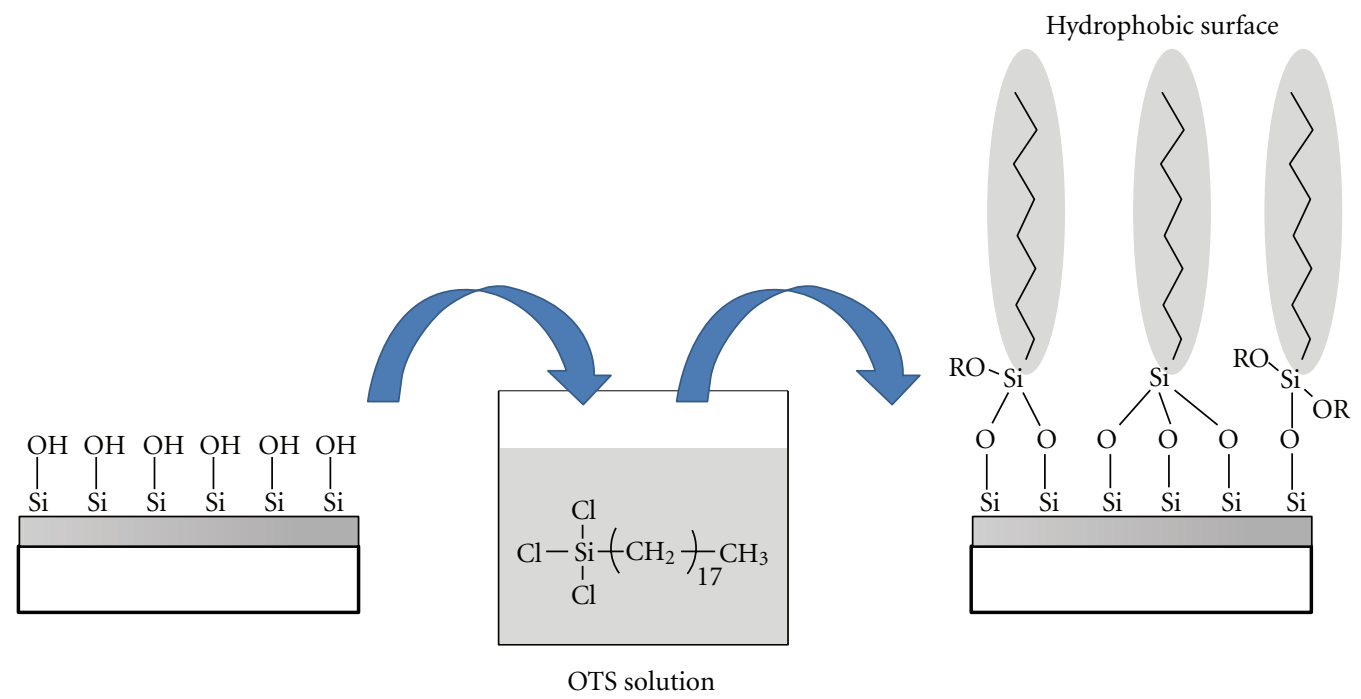

FIgURE 9: Surface modification of PMSQ film with alkyltrichlorosilane.

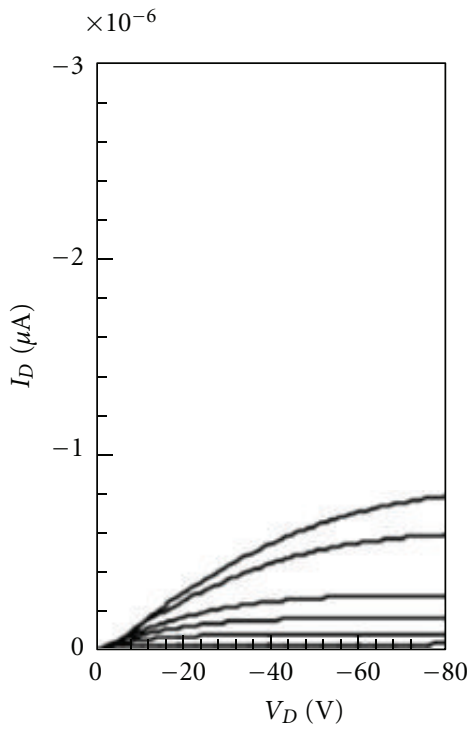

(a)

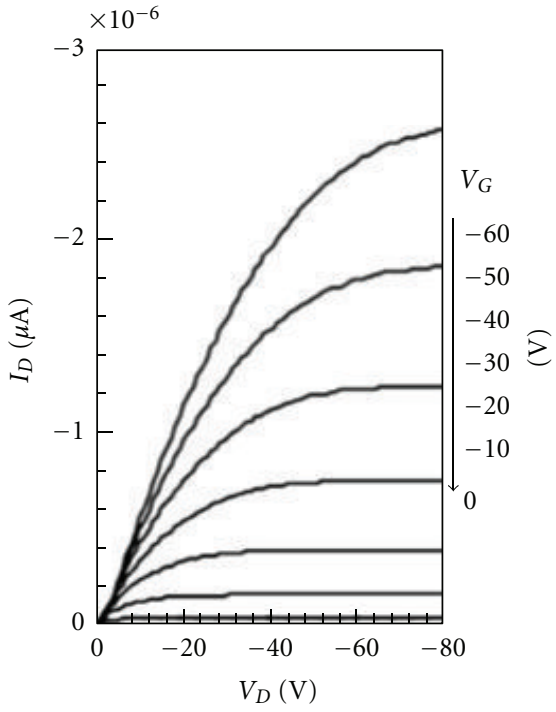

(b)

FIGURE 10: Output characteristics of P3HT TFTs fabricated on (a) non-treated PMSQ film and (b) OTS-treated PMSQ film, at gate voltages $V_{G}=0,-10,-20,-30,-40,-50$, and $-60 \mathrm{~V}$.

result follows the same tendency of SAM-modified thermal grown $\mathrm{SiO}_{2}$, and it was concluded that co-PMSQ prepared from cocondensation is an effective gate-insulating materials with a highly hydrophobic surface.

5.2. Improvement of Permittivity of PMSQ. As driving OTFTs with low operating voltage is an important function for a high performance device, the gate-insulating layer of high permittivity is required. We have also tried to develop polysilsesquioxane having high permittivity. Some modified PMSQs were synthesized by cocondensation of several alkyltrialkoxysilanes and methyltrimethoxysilane. It revealed that the introduction of polar functional groups, such as epoxy and cyano, leads to the co-PMSQs with high permittivity. Co-PMSQ containing epoxy group (PMSQepoxy) showed very high permittivity, although TFT properties with PMSQ-epoxy gate-insulating layer was not superior, because hydroxyl groups generated by ring-opening of epoxy groups affected the charge trapping. On the other hand, co-PMSQ containing cyano group (PMSQ-CN), which is a product from cocondensation with cyanoethyltrimethoxysilane, improved permittivity with the increase of cyano group 
<smiles>CO[Si](C)(OC)OC</smiles>

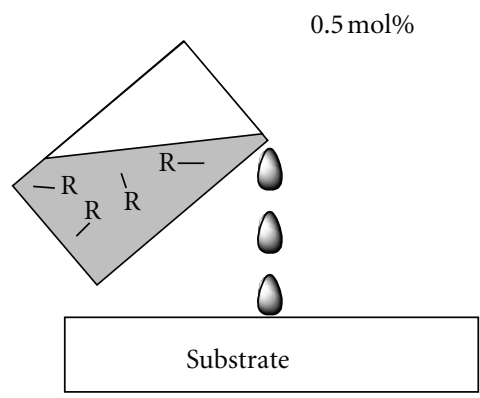

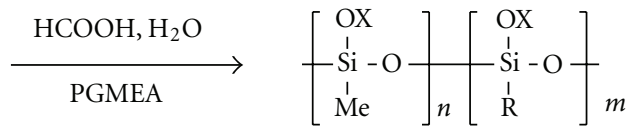

Co-PMSQ

$$
\begin{aligned}
\mathrm{X}= & \mathrm{H}, \mathrm{Me}, \mathrm{Si} \\
\mathrm{R}= & -\left(\mathrm{CH}_{2}\right)_{17} \mathrm{CH}_{3} \\
& -\left(\mathrm{CH}_{2}\right)_{2}\left(\mathrm{CF}_{2}\right)_{5} \mathrm{CF}_{3} \\
& -\left(\mathrm{CH}_{2}\right)_{2} \mathrm{Ph}
\end{aligned}
$$

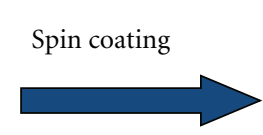

Cured at $150^{\circ} \mathrm{C}$
Hydrophobic surface

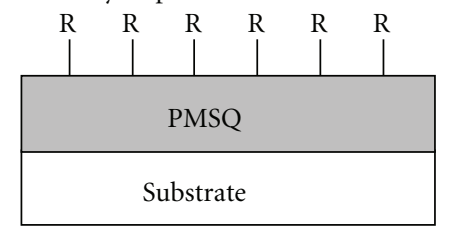

Figure 11: Synthesis of co-PMSQ and fabrication of the hydrophobic gate-insulating layers.

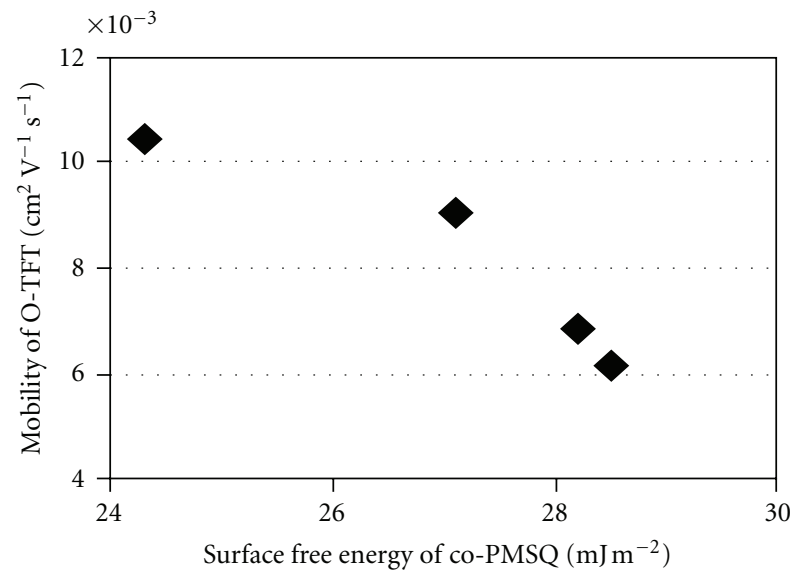

FIGURE 12: Relationships between mobility of O-TFTs and surface free energy of co-PMSQ gate-insulating layer.

as shown in Figure 13 [24]. When the feed ratio of cyano group was $1: 1$, the permittivity was 3 times larger than that of PMSQ without cyano group. Although PMSQ-CN had slightly less hydrophobic surface than that of normal PMSQ, field-effect mobility using two gate-insulating layer did not differ much. The field-effect mobility $(\mu)$ of O-TFTs with PMSQ and PMSQ-CN are $3.7 \times 10^{-3} \mathrm{~cm}^{2} \mathrm{~V}^{-1} \mathrm{~s}^{-1}$ and $2.8 \times$ $10^{-3} \mathrm{~cm}^{2} \mathrm{~V}^{-1} \mathrm{~s}^{-1}$, respectively. As clearly shown in Figure 13, $I_{D}$ of the P3HT TFT with gate-insulating layer of PMSQ$\mathrm{CN}$ was ca. 4 times larger than that of PMSQ without cyano groups at $V_{G}=-30 \mathrm{~V}$. This result suggested that required $V_{G}$ to obtain a certain $I_{D}$ could be lowered by using PMSQ-CN gate-insulating layer, and thus, PMSQ-CN revealed to be a promising gate-insulating material for the high-performance O-TFT of low-operating voltage.

5.3. Photocurable PMSQ. A photolithography is indispensable process for the fabrication of electric devices using photoresists and UV irradiation. Introduction of photocurability to PMSQ is seemed to become applicable not only for O-TFT, but also various electronic devices. Therefore, the photocurable PMSQ was investigated by introducing photofunctional acrylic groups [27]. As shown in Figure 14, a sol-gel cocondensation of methyltrimethoxysilane and acryloxypropyltrimethoxysilane was carried out under the same condition that have already described above. The spincoated film of thus obtained copolysilsesquioxane (PMSQacryl) with Darocure 1173 as a photoradical initiator was exposed to UV light through a photo mask, then the $250 \mu \mathrm{m}$ line and space negative-patterns were obtained by the development with 2-propanol. As shown in the inset table in Figure 14, the increasing acrylic groups in PMSQ lead to slightly decrease of electric resistivity. However, these values of resistivity are sufficient for gate-insulating materials of O-TFT. Also, it was found that the thin film from PMSQ-acryl exhibited no permittivity change even in higher temperature by the impedance spectroscopy, which was indicating no existence of ionic impurities. The properties of O-TFT with PMSQ-acryl as a gate-insulating layer were comparable to that with normal PMSQ. These results have suggested that the photo-curable PMSQ is not only useful material as a gate-insulating layer of O-TFT but also promising insulating material for other electronic devices.

\section{Conclusion}

The term of "printed electronics" refers to electronic devices fabricated by solution processes, which are less energy consumption and cost comparing to vacuum processes. For the sake of achieving printed electronics, there should be close connection between three research steps of material development, process design, and device characterization. We have developed PMSQ derivatives for gate-insulating layer of O-TFT based on three research steps. Possessing the property of both organic and inorganic materials, one of the typical organic-inorganic hybrid materials, polysilsesquioxane, has been revealed to be an important field of materials for printed electronics. The careful investigation of 


\begin{tabular}{|c|c|c|c|c|}
\hline \multicolumn{2}{|c|}{$\begin{array}{c}\mathrm{OMe} \\
\text { ! } \\
\mathrm{MeO}-\mathrm{Si}-\mathrm{OMe}- \\
\stackrel{\mathrm{C}}{\mathrm{CH}_{3}}\end{array}$} & $\begin{array}{l}\mathrm{OMe} \\
\text {-Si-OMe } \\
\underbrace{1}-\mathrm{OMe}\end{array}$ & $\underset{\text { PGMEA }}{\stackrel{\mathrm{HCOOH}, \mathrm{H}_{2} \mathrm{O}}{\longrightarrow}}$ & $\underbrace{\mathrm{OR}}_{y}$ \\
\hline$x: y$ & $\mathrm{Mw}$ & $\mathrm{Mw} / \mathrm{Mn}$ & $\begin{array}{c}\text { Dielectric constant } \\
(10 \mathrm{kHz})\end{array}$ & $\begin{array}{c}\text { Contact } \\
\text { angle }\end{array}$ \\
\hline $1: 0$ & 10600 & 4.96 & 4.6 & 88 \\
\hline $3: 1$ & 11300 & 3.9 & 8.4 & 85 \\
\hline $2: 1$ & 7500 & 3.87 & 9.9 & 84 \\
\hline $1: 1$ & 4200 & 2.43 & 13.7 & 79 \\
\hline
\end{tabular}

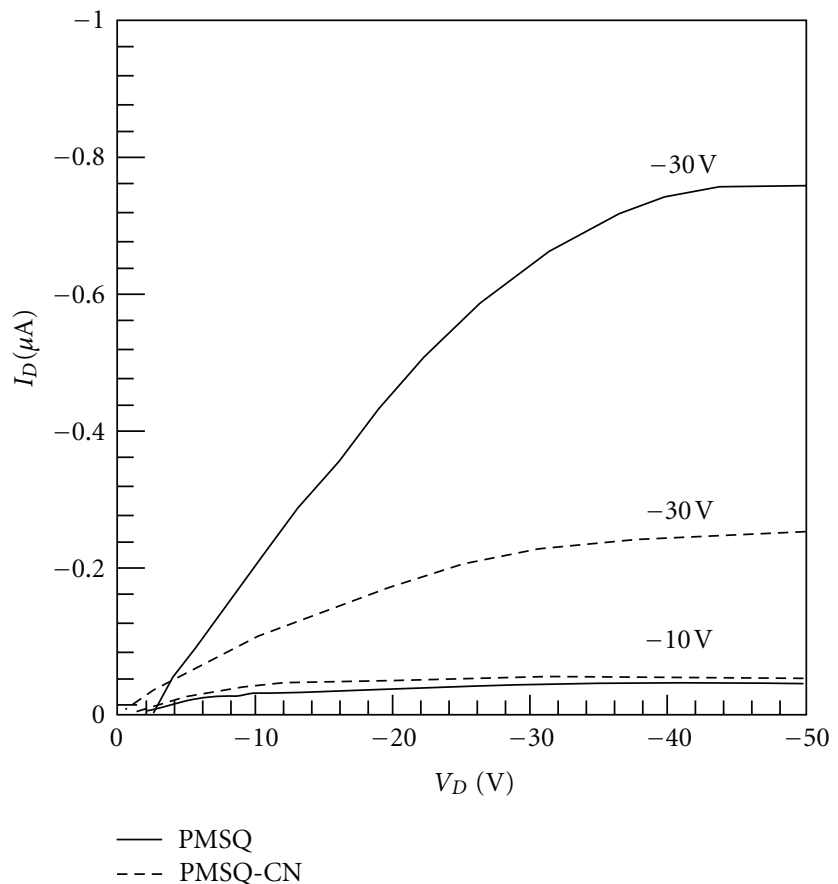

(a)

(b)

FIGURE 13: Synthesis of copolysilsesquioxane (PMSQ-CN) and their properties (a), and output characteristics of P3HT TFT with PMSQ gate-insulating layer (dashed lines) and PMSQ-CN gate-insulating layer (solid lines) at $V_{G}=-10$ and $-30 \mathrm{~V}$ (b).

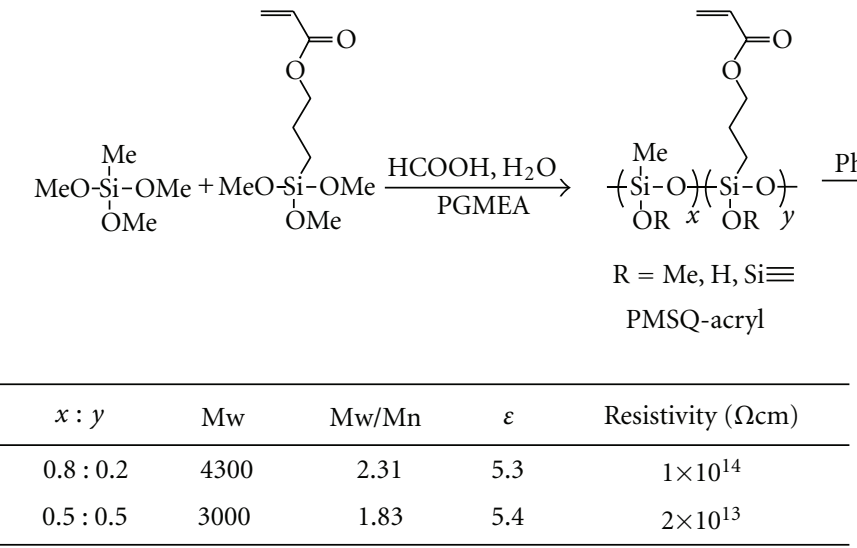

(a) Estimated by GPC in THF using polystyrene standards.

(b) Baking temperature: $100^{\circ} \mathrm{C}$ for $1 \mathrm{~h}$ and $150^{\circ} \mathrm{C}$ for $1 \mathrm{~h}$.

(c) Measured at $1 \mathrm{kHz}$. $\stackrel{\text { Photocuring }}{\longrightarrow}$ Crosslinked PMSQ

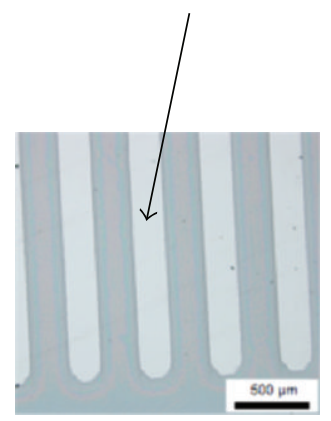

FIGURE 14: Synthesis of copolysilsesquioxane (PMSQ-acryl) and their properties.

the preparation condition of PMSQs has enabled the development of material suitable for gate-insulating layer of $\mathrm{O}$ TFTs. Recently, we have fabricated flexible O-TFT utilizing PMSQ described above, and succeeded to drive an electricpaper device. The property adjustability of PMSQ, that is, resistivity, surface hydrophobicity, permittivity, and photocurability, suggests further possibility of applications. We are certainly expecting the polysilsesquioxane derivatives to be one of key materials for new electronic devices.

\section{References}

[1] H. Sirringhaus, P. J. Brown, R. H. Friend et al., "Twodimensional charge transport in self-organized, high-mobility 
conjugated polymers," Nature, vol. 401, no. 6754, pp. 685-688, 1999.

[2] A. Afzali, C. D. Dimitrakopoulos, and T. L. Breen, "Highperformance, solution-processed organic thin film transistors from a novel pentacene precursor," Journal of the American Chemical Society, vol. 124, no. 30, pp. 8812-8813, 2002.

[3] T. Kawase, H. Sirringhaus, R. H. Friend, and T. Shimoda, "Inkjet printed via-hole interconnections and resistors for allpolymer transistor circuits," Advanced Materials, vol. 13, no. 21, pp. 1601-1605, 2001.

[4] H. Klauk, M. Halik, U. Zschieschang, G. Schmid, W. Radlik, and W. Weber, "High-mobility polymer gate dielectric pentacene thin film transistors," Journal of Applied Physics, vol. 92, no. 9, p. 5259, 2002.

[5] J. A. Rogers, Z. Bao, A. Makhija, and P. Braun, "Printing process suitable for reel-to-reel production of high-performance organic transistors and circuits," Advanced Materials, vol. 11, no. 9, pp. 741-745, 1999.

[6] C. D. Sheraw, D. J. Gundlach, and T. N. Jockson, "Spinon polymer gate dielectric for high performance organic thin film transistors," Materials Research Society Symposium Proceedings, vol. 558, article 403, 2000.

[7] T. B. Singh, F. Meghdadi, S. Günes et al., "High-performance ambipolar pentacene organic field-effect transistors on poly(vinyl alcohol) organic gate dielectric," Advanced Materials, vol. 17, no. 19, pp. 2315-2320, 2005.

[8] D. Knipp, R. A. Street, A. Vokel, and J. Ho, "Pentacene thin film transistors on inorganic dielectrics: morphology, structural properties, and electronic transport," Journal of Applied Physics, vol. 93, no. 1, article 347, 9 pages, 2003.

[9] J. Wang, X. Yan, Y. Xu, J. Zhang, and D. Yan, "Organic thin-film transistors having inorganic/organic double gate insulators," Applied Physics Letters, vol. 85, no. 22, article 5424, 3 pages, 2004.

[10] A. Facchetti, M. H. Yoon, and T. J. Marks, "Gate dielectrics for organic field-effect transistors: new opportunities for organic electronics," Advanced Materials, vol. 17, no. 14, pp. 1705$1725,2005$.

[11] Z. Bao, V. Kuck, J. A. Rogers, and M. A. Paczkowski, "Silsesquioxane resins as high-performance solution processible dielectric materials for organic transistor applications," Advanced Functional Materials, vol. 12, no. 8, pp. 526-531, 2002.

[12] P. Liu, Y. Wu, Y. Li, B. S. Ong, and S. Zhu, "Enabling gate dielectric design for all solution-processed, high-performance, flexible organic thin-film transistors," Journal of the American Chemical Society, vol. 128, no. 14, pp. 4554-4555, 2006.

[13] Y. Wu, P. Lin, and B. S. Ong, "Organic thin-film transistors with poly(methyl silsesquioxane) modified dielectric interfaces," Applied Physics Letters, vol. 89, no. 1, Article ID 013505, 2006.

[14] S. Jeong, D. Kim, S. Lee, B. K. Park, and J. Moon, Applied PhysicsLetters, vol. 89, Article ID 092101, 2006.

[15] S. Jeong, D. Kim, S. Lee, B. K. Park, and J. Moon, "Influence of silanol groups on the electrical performance of organic thin-film transistors utilizing organosiloxane-based organicinorganic hybrid dielectrics," Nanotechnology, vol. 18, no. 2, Article ID 025204, 2007.

[16] K. Tomatsu, T. Hamada, T. Nagase et al., "Fabrication and characterization of poly(3-hexylthiophene)-based fieldeffect transistors with silsesquioxane gate insulators," Japanese Journal of Applied Physics, vol. 47, no. 4, pp. 3196-3199, 2008.

[17] T. Nagase, T. Hamada, K. Tomatsu et al., "Low-temperature processable organic-inorganic hybrid gate dielectrics for solution-based organic field-effect transistors," Advanced Materials, vol. 22, no. 42, pp. 4706-4710, 2010.

[18] S. Y. Yang, S. H. Kim, K. Shin, H. Jeon, and C. E. Park, "Low-voltage pentacene field-effect transistors with ultrathin polymer gate dielectrics," Applied Physics Letters, vol. 88, no. 17, Article ID 173507, 3 pages, 2006.

[19] S. Uemura, "Low-frequency dielectric behavior of poly(vinylidene fluoride)," Journal of Polymer Science, vol. 12, no. 6, pp. 1177-1188, 1974.

[20] J. Veres, S. Ogier, G. Lloyd, and D. de Leeuw, "Gate insulators in organic field-effect transistors," Chemistry of Materials, vol. 16, no. 23, pp. 4543-4555, 2004.

[21] A. Salleo, M. L. Chabinyc, M. S. Yang, and R. A. Street, "Polymer thin-film transistors with chemically modified dielectric interfaces," Applied Physics Letters, vol. 81, no. 23, pp. 43834385, 2002.

[22] K. P. Pernstich, S. Haas, D. Oberhoff et al., "Threshold voltage shift in organic field effect transistors by dipole monolayers on the gate insulator," Journal of Applied Physics, vol. 96, no. 11, pp. 6431-6438, 2004.

[23] S. Yamazaki, T. Hamada, K. Tomatsu et al., "Electrical characteristics of polymer field-effect transistors with poly(methylsilsesquioxane) gate dielectrics on plastic substrates," Thin Solid Films, vol. 517, no. 4, pp. 1343-1345, 2008.

[24] T. Hamada, S. Yamazaki, T. Nagase et al., "Chemical design of polysilsesquioxane as a gate insulator for organic thin-film transistors," in Proceedings of the 15th International Display Workshops (IDW'08), pp. 1665-1668, December 2008.

[25] T. Hamada, T. Nagase, T. Kobayashi, K. Matsukawa, and H. Naito, "Effective control of surface property on poly(silsesquioxane) films by chemical modification," Thin Solid Films, vol. 517, no. 4, pp. 1335-1339, 2008.

[26] M. Watanabe, K. Muro, T. Hamada et al., "Surface modification of organic-inorganic hybrid insulator for printable organic field-effect transistors," Chemistry Letters, vol. 38, no. 1, pp. 34-35, 2009.

[27] T. Hamada, T. Nagase, M. Watanabe, S. Watase, H. Naito, and K. Matsukawa, "Preparation and dielectric property of photocurable polysilsesquioxane hybrids," Journal of Photopolymer Science and Technology, vol. 21, no. 2, pp. 319-320, 2008. 

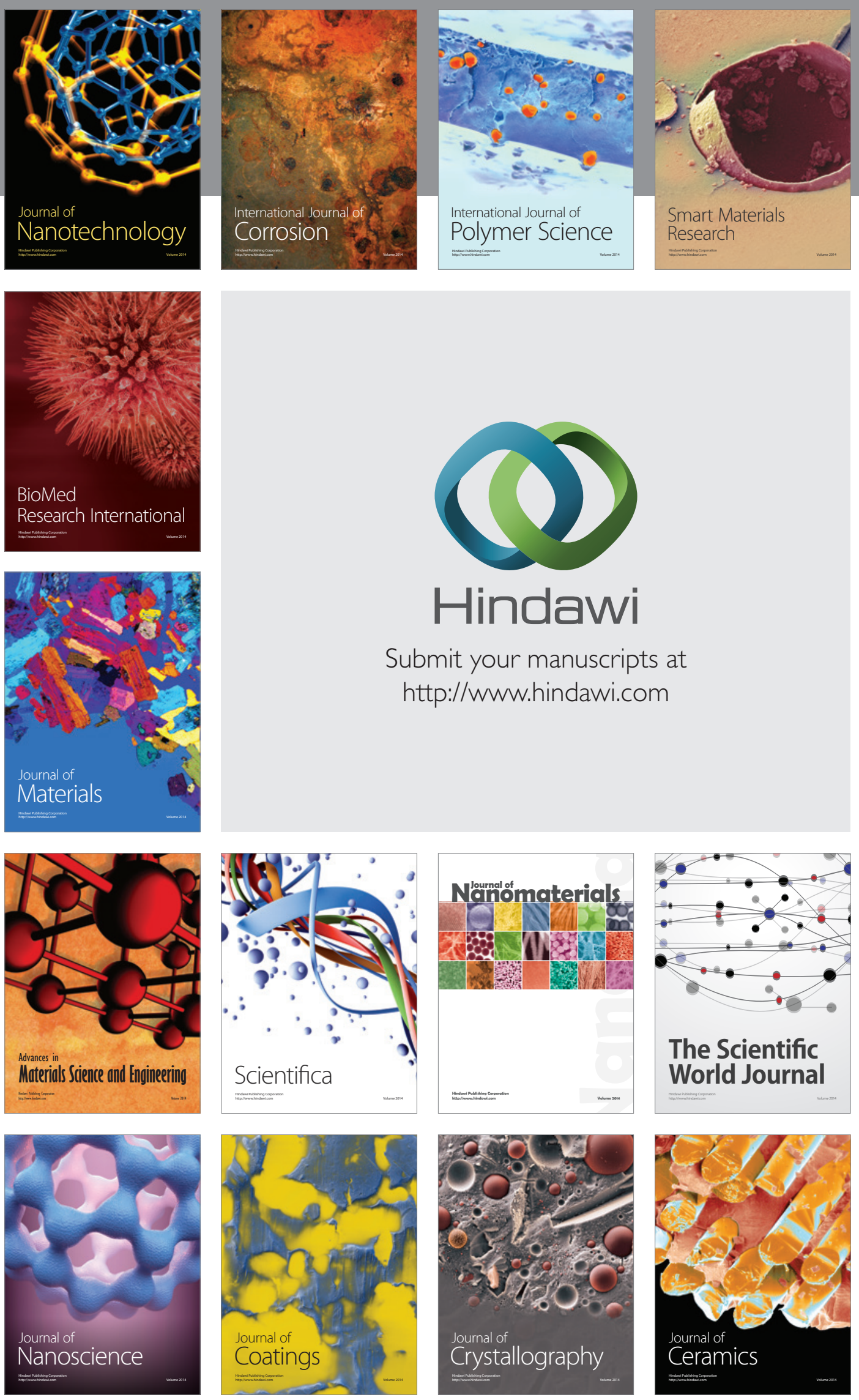

The Scientific World Journal

Submit your manuscripts at

http://www.hindawi.com

\section{World Journal}

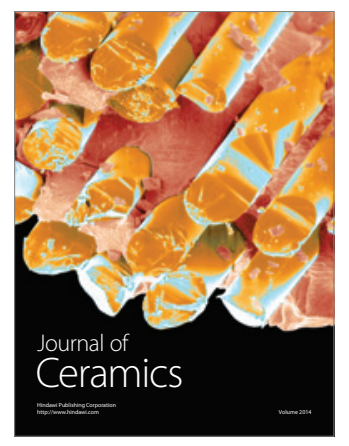

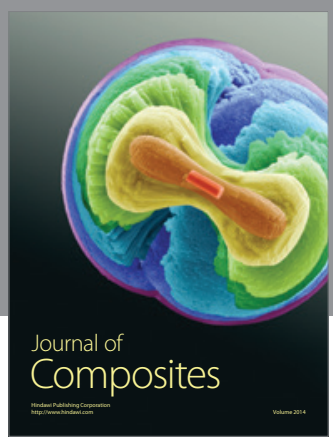
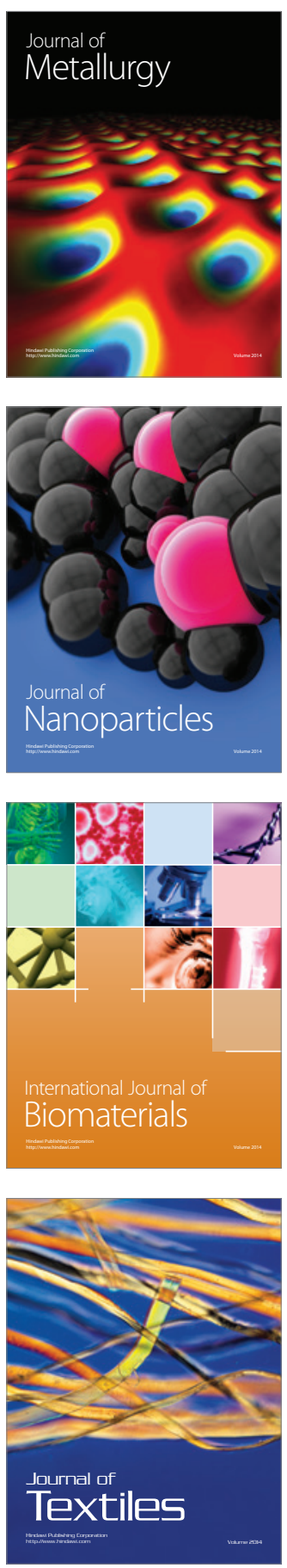